\title{
An analysis of the immunological tumor microenvironment of primary tumors and regional lymph nodes in squamous cell lung cancer
}

\author{
Yoshinobu Ichiki $^{1,2}$, Mari Ueno ${ }^{3}$, Shinya Yanagi ${ }^{3}$, Yoshiro Kanasaki ${ }^{1}$, Hidenori Goto ${ }^{1}$, Takashi Fukuyama ${ }^{4}$, \\ Shuji Mikami ${ }^{3}$, Kozo Nakanishi ${ }^{1}$, Tsuyoshi Ishida ${ }^{3}$ \\ ${ }^{1}$ Department of General Thoracic Surgery, National Hospital Organization, Saitama Hospital, Wako, Japan; ${ }^{2}$ Second Department of Surgery, \\ University of Occupational and Environmental Health, School of Medicine, Kitakyushu, Japan; ${ }^{3}$ Department of Diagnostic Pathology, National \\ Hospital Organization, Saitama Hospital, Wako, Japan; ${ }^{4}$ Division of Biomedical Research, Kitasato University Medical Center, Kitamoto, Japan \\ Contributions: (I) Conception and design: Y Ichiki, M Ueno; (II) Administrative support: Y Ichiki, M Ueno, T Fukuyama; (III) Provision of study \\ materials or patients: Y Ichiki; (IV) Collection and assembly of data: Y Ichiki, Y Kanasaki, H Goto, K Nakanishi; (V) Data analysis and interpretation: \\ Y Ichiki, M Ueno, S Yanagi, S Mikami, T Ishida; (VI) Manuscript writing: All authors; (VII) Final approval of manuscript: All authors. \\ Correspondence to: Yoshinobu Ichiki, MD, PhD. Department of General Thoracic Surgery, National Hospital Organization Saitama Hospital, 2-1 \\ Suwa, Wako, Saitama, 351-0102, Japan. Email: y-ichiki@med.uoeh-u.ac.jp.
}

Background: Various immune cells that play a central role in antitumor immunity accumulate in primary tumors and regional lymph nodes. Such cellular accumulation and the molecular expression were analyzed to elucidate the immunological tumor microenvironment.

Methods: Fifty squamous cell lung cancer patients with complete resection were included. Resected specimens from primary lung tumors and regional lymph nodes were immunostained for immune-related molecules, such as CD8, CD103, major histocompatibility complex (MHC) class I, and programmed cell death protein ligand-1 (PD-L1), and the relationship between the prognosis and clinicopathological factors was retrospectively analyzed.

Results: Tumor-infiltrating lymphocytes and CD8+ lymphocytes, intratumoral and intrastromal CD103+ lymphocytes, tumor diameter, pathological $\mathrm{T}$ and $\mathrm{N}$ factors, and pathological stage were significant prognostic factors for the disease-specific survival (DSS) in a univariate analysis. In a multivariate analysis, intratumoral and intrastromal CD103+ lymphocytes and pathological $\mathrm{T}$ and $\mathrm{N}$ factors were independent prognostic factors of the DSS. Significant concordance was found between the PD-L1 expression of primary tumors and metastatic lymph nodes as well as among tumor-infiltrating lymphocytes, CD8+ lymphocytes and CD103+ lymphocytes. Infiltration of CD103+ lymphocytes into the tumor was significantly correlated with an increased PD-L1 expression of cancer cells in both primary tumors and reginal lymph node metastases. Both the intratumoral infiltration of CD103+ lymphocytes and PD-L1 expression of cancer cells were significantly higher in lymph node metastases than in primary tumors.

Conclusions: CD103+ lymphocyte infiltration in the primary tumor was shown to be strongly involved in the prognosis.

Keywords: Lung cancer; CTL; CD103; programmed cell death protein ligand-1 (PD-L1); tumor immunology

Submitted Jun 10, 2021. Accepted for publication Aug 19, 2021.

doi: $10.21037 /$ tlcr-21-479

View this article at: https://dx.doi.org/10.21037/tlcr-21-479 


\section{Introduction}

While immune checkpoint inhibitors (ICIs) have excellent therapeutic efficacy as a standard treatment for lung cancer and prolong the survival period, the response rate of a single agent is about $20-40 \%(1-4)$, and the mechanism is often unclear. To clarify the mechanism underlying the effects of ICIs, it is essential to elucidate the immune response evoked locally in the tumor in detail.

We previously focused on the local immune response of the tumor and reported that cytotoxic $\mathrm{T}$ lymphocytes (CTLs) and B lymphocytes that recognized cancer-specific mutated p53 in a lung cancer case locally invaded the tumor and caused a cancer-specific immune response (5). While cancer-specific CTLs and B lymphocytes accumulate in the tumor microenvironment and cause a cancer-specific immune response, immune cells, such as regulatory $\mathrm{T}$ lymphocytes, myeloid-derived suppressive cells (MDSCs), and macrophages, also exist in the tumor microenvironment and regional lymph nodes and induce their own cancerspecific immune response. In addition, the immunerelated molecules that control the functions of immune cells and cancer cells are diverse in nature and temporally and spatially changing. Many aspects of how the immune response evoked in the primary tumor or regional lymph nodes is regulated and leads to an effective antitumor immune response are unclear.

Tumor-infiltrating lymphocytes (TILs) are considered to play a central role in antitumor immune surveillance $(6,7) \cdot \mathrm{CD} 8+\mathrm{T}$ lymphocytes are the major population of $\mathrm{T}$ lymphocytes that cause an actual antitumor immune response. CD8+ TILs were reported to be a favorable independent prognostic factor $(8,9)$. CD103, also known as integrin $\alpha \mathrm{E} \beta 7$ (ITGAE), is a transmembrane heterodimer complex involved in cell-to-cell to matrix interactions (10). CD103 interacts with E-cadherin expressed in epithelial cells and mediates cell adhesion, migration, and cell lymphocyte homing (11). Therefore, CD103 is considered a specific molecule of immune cells that resides within the epithelium of mucosal organs, including the genital tract, stomach, lung, and skin (12-15). CD103+ TILs were also reported as a favorable prognostic factor (16-19). In the present study we analyzed the prognostic effects of molecules expressed on these effector immune cells in patients undergoing surgery for squamous cell lung cancer.

Programmed cell death protein-1 (PD-1) is expressed on the cell surface of $\mathrm{T}$ lymphocytes and regulates hyperautoimmune responses. Programmed cell death protein ligand-1 (PD-L1), which is an immune-modulating ligand of $\mathrm{PD}-1$, is expressed on antigen-presenting cells as well as cancer cells. Recently, ICIs were administered to patients with non-small-cell lung cancer (NSCLC) and demonstrated marked efficacy, even for chemotherapyresistant patients $(1,2)$. Since ICIs block immune checkpoint molecules expressed on cancer cells or immune cells, they can block inhibitory signals from ligands and prolong T lymphocyte activation (20). Therefore, the PD-L1 expression on cancer cells or immune cells is an important factor involved in the antitumor immune response.

An elevated neutrophil-to-lymphocyte ratio (NLR) was reported to be a poor prognostic factor in solid tumors, including NSCLC, according to a high-quality metaanalysis (21). An elevated platelet-to-lymphocyte ratio (PLR) was also shown to be associated with a poor survival in NSCLC patients $(22,23)$. Diem et al. reported that elevated NLR and PLR values before treatment were associated with a poor overall survival (OS), progression-free survival (PFS), and response rate in patients with metastatic NSCLC treated with nivolumab (24). The NLR and PLR are strongly related to the immune status and have been reported as prognostic factors, so they were included in our analysis.

In the present study, we investigated the relationship between clinicopathological factors and the prognosis in 50 squamous cell lung cancer patients undergoing complete resection, with a particular focus on the following points:

(I) Effect of clinical factors, such as the NLR and PLR, which are related to the immune status, on the prognosis;

(II) Effect of effector cell infiltration in primary tumors and regional lymph nodes and the expression of CD8 and CD103, which are molecules specific to effector cells, on the prognosis;

(III) Effect of the PD-L1 expression of cancer and immune cells in primary tumors and regional lymph nodes on the prognosis;

(IV) Effect of the downregulation of major histocompatibility complex (MHC) class I expression of cancer cells in primary tumors and regional lymph node metastases, which is known to be the major escape mechanism of cancer cells, on the prognosis;

(V) Differences in the immunological tumor microenvironment between primary tumors and regional lymph nodes.

We present the following article in accordance with the 

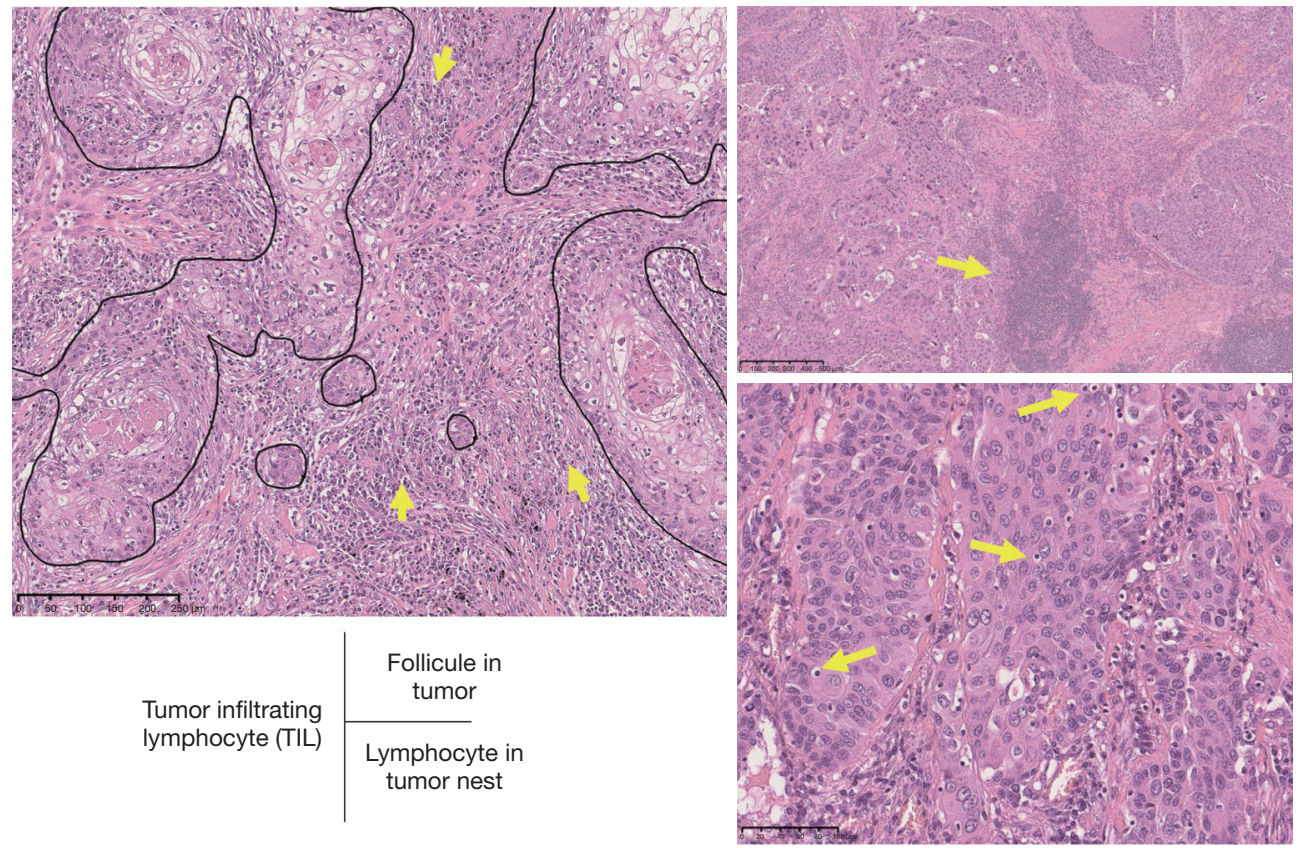

Figure 1 Evaluation of tumor infiltrating lymphocytes. HE-stained specimens of excised sections were used to evaluate TILs (proportion of lymphocytes in the tumor stroma area), lymphoid follicle formation, and lymphocyte infiltration into tumor nests. The presence of lymphoid follicles in the tumor and infiltrating lymphocytes in tumor nests was also confirmed. Typical cases are presented. The arrows in the left panel represent TILs, the arrow in the upper right panel represents lymphoid follicles, and the arrows in the lower right panel represent lymphocytes in the tumor nests. The enclosed areas in the left panel show tumor nests. HE, hematoxylin and eosin; TILs, tumor-infiltrating lymphocytes.

REMARK reporting checklist (25) (available at https:// dx.doi.org/10.21037/tlcr-21-479).

\section{Methods}

\section{Patients and samples}

From August 2009 to June 2019, 50 patients with lung squamous cell carcinoma who underwent complete resection by lobectomy in our department were included in the analysis. The pathological stage (p-stage) was decided based on the current tumor, node, metastasis (TNM) classification (26). In addition, the NLR and PLR were calculated from preoperative blood sampling data. The relationship between these clinicopathologic factors and the prognosis was retrospectively analyzed.

This analysis was performed based on the Declaration of Helsinki (as reviewed in 2013), and the protocol was approved by Saitama Hospital Ethics Committee (R201901). Written informed consent was obtained from all the participants for publication of this study.

\section{Immunobistochemistry (IHC)}

Hematoxylin and eosin (HE)-stained specimens of excised sections were used to evaluate TILs (proportion of lymphocytes in the tumor stroma area), lymphoid follicle formation, and lymphocyte infiltration into tumor nests. TILs were evaluated according to a previous report (6). The presence of lymphoid follicles in the tumor and infiltrating lymphocytes in the tumor nests was also confirmed (Figure 1).

Serial sections from paraffin-embedded tumors were stained with anti-CD8 (SP57), anti-CD103 (Abcam, Cambridge, UK), anti-PD-L1 (SP263), and anti-MHC class I [human leukocyte antigen (HLA)-A,B,C] (D3703H) (EMR8-5.1) MBL. The Benchmark XT autostainer (Ventana Medical System, Tucson, AZ, USA) was used for IHC. For the evaluation of CD $8+$ and CD103+ lymphocytes, two pathologists used the same method as for TILs to count the proportion of the tumor stroma area where IHC-positive lymphocytes were present. The analysis was then performed using the median value. CD103+ cells were evaluated separately for lymphocytes that 
Table 1 Patient characteristics

\begin{tabular}{|c|c|}
\hline Variables & Number \\
\hline Age, years, median [range] & $74[57-88]$ \\
\hline \multicolumn{2}{|l|}{ Sex } \\
\hline Male & $37(74 \%)$ \\
\hline Female & $13(26 \%)$ \\
\hline Brinkman index, median [range] & $1,000[0-3,480]$ \\
\hline \multicolumn{2}{|l|}{ Performance status } \\
\hline 0 & $42(84 \%)$ \\
\hline 1 & $8(16 \%)$ \\
\hline \multicolumn{2}{|l|}{$p-T$} \\
\hline 1 & $26(52 \%)$ \\
\hline 2 & $18(36 \%)$ \\
\hline 3 & $4(8 \%)$ \\
\hline 4 & $2(4 \%)$ \\
\hline \multicolumn{2}{|l|}{$\mathrm{p}-\mathrm{N}$} \\
\hline 0 & $41(82 \%)$ \\
\hline 1 & $8(16 \%)$ \\
\hline 2 & $1(2 \%)$ \\
\hline \multicolumn{2}{|l|}{ p-stage } \\
\hline I & $36(72 \%)$ \\
\hline II & $11(22 \%)$ \\
\hline III & $3(6 \%)$ \\
\hline Tumor size, mm, median [range] & $22[3-75]$ \\
\hline NLR, median [range] & $2.392[0.72-7.471]$ \\
\hline PLR, median [range] & $125.7[39.6-350.2]$ \\
\hline
\end{tabular}

NLR, neutrophil to lymphocyte ratio; PLR, platelet to lymphocyte ratio.

infiltrated the tumor nest (CD103 tumoral), lymphocytes that infiltrated the tumor stroma (CD103 stromal), and lymphocytes that infiltrated both the tumor nest and stroma (CD103 total). Regarding the expression of MHC class I, the ratio of cancer cells expressing MHC class I among the viable cancer cells was used. To evaluate the PD-L1 expression in regional lymph nodes, the proportion of IHC-positive immune cells among the immune cells in the lymph nodes was calculated. The ratio of the area of IHCpositive cancer cells to the total area of viable cancer cells was calculated to evaluate the PD-L1 expression in cancer cells. Regarding the expression of CD103 in the regional lymph nodes, the ratio of IHC-positive lymphocyte cells among the lymphocytes was examined in the same manner (LN CD103 stromal). In cases with regional lymph node metastases, the proportion of CD103+ positive lymphocytes among lymphocytes infiltrating the tumor nests was calculated (LN CD103 tumoral). In 9 cases (18\%), metastasis was observed in the regional lymph nodes.

\section{Statistical analyses}

The Kaplan-Meier method was used for the survival analysis, the log-rank test was used for the univariate analysis, and a Cox proportional hazard model was used for the multivariate analysis.

A receiver operating characteristics (ROC) curve analysis was used to determine the cut-off values of the obtained clinicopathological data. The $t$-test and Pearson's productmoment correlation coefficient were used to compare the molecular expression. All $\mathrm{P}$ values were two-sided. When the $\mathrm{P}$ value was $<0.05$, we regarded it as a significant difference. Statistical analyses were performed with EZR (Saitama Medical Center, Jichi Medical University, Saitama, Japan), which is a graphical user interface for $\mathrm{R}$ (The $\mathrm{R}$ Foundation for Statistical Computing, Vienna, Austria). More precisely, it is a modified version of $\mathrm{R}$ commander designed to add statistical functions frequently used in biostatistics (27).

\section{Results}

\section{Patient characteristics}

The patients' characteristics are presented in Table 1. The cohort comprised 37 men (74\%) and 13 women (26\%) with a median age at surgery of 74 (range, 57-88) years old. There were $42(84 \%)$ and $8(16 \%)$ cases of Eastern Cooperative Oncology Group (ECOG) performance status (PS) 0 and 1, respectively. There were 36, 11, and 3 cases of pathological stage I, II, and III, respectively. Seven of 50 patients received adjuvant chemotherapy. There were 2 cases of UFT and 5 cases of cisplatin + vinorelbine. None of the patients received neoadjuvant chemotherapy. The observation period was 16-3,643 days (median: 1,218 days). The 5 -year OS rate was $60.0 \%$, and the median survival was 2,044 days. The 5-year disease-specific and diseasefree survival rates were $82.7 \%$ and $70.9 \%$, respectively (Figure 2). 

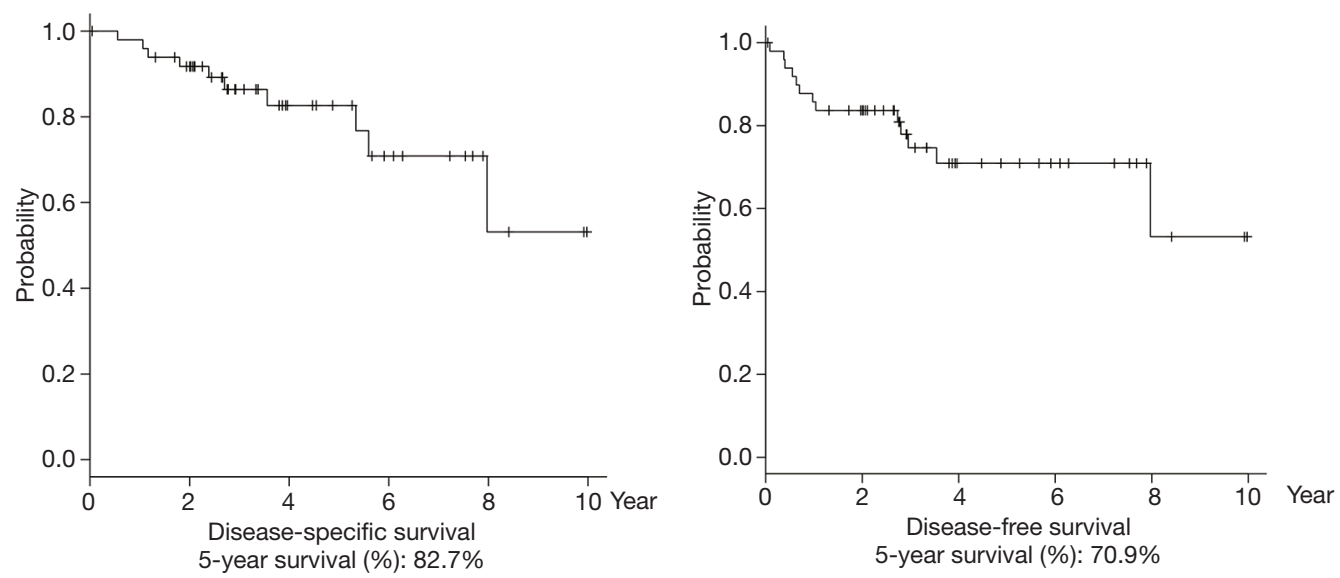

Figure 2 The disease-specific survival and disease-free survival. Kaplan-Meier curves of the disease-specific and disease-free survival are shown. The 5-year disease-specific and disease-free survival rates were $82.7 \%$ and $70.9 \%$, respectively.

Table 2 Pathological characteristics

\begin{tabular}{|c|c|}
\hline Variables & Number \\
\hline TIL, \%, median [range] & $40[7.5-80.0]$ \\
\hline \multicolumn{2}{|l|}{ Follicule in tumor } \\
\hline Positive & $27(54 \%)$ \\
\hline Negative & $23(46 \%)$ \\
\hline \multicolumn{2}{|l|}{ Lymphocyte in tumor nest } \\
\hline Positive & $30(60 \%)$ \\
\hline Negative & $20(40 \%)$ \\
\hline CD8, \%, median [range] & $6[0-56]$ \\
\hline CD103 (tumoral), \%, median [range] & $25[0-79]$ \\
\hline CD103 (stromal), \%, median [range] & $3[0-28]$ \\
\hline CD103 (total), \%, median [range] & $4[0-56]$ \\
\hline MHC class I, \%, median [range] & 80 [0-99] \\
\hline PD-L1 (TCS), \%, median [range] & $5[0-97.5]$ \\
\hline PD-L1 (ICS), \%, median [range] & $2.5[0-50]$ \\
\hline LN-PD-L1 (ICS), \%, median [range] & $30[0-75]$ \\
\hline LN-PD-L1 (TCS), \%, median [range] & $20[0-75]$ \\
\hline LN-CD103 (stromal), \%, median [range] & $0[0-32.5]$ \\
\hline LN-CD103 (tumoral), \%, median [range] & $70[7.5-97.5]$ \\
\hline
\end{tabular}

TIL, tumor infiltrating lymphocytes; MHC, major histocompatibility complex; PD-L1, programmed cell death protein ligand-1; TCS, tumor cell score; ICS, immune cell score; LN, lymph node.

\section{Pathological analyses}

The data obtained by the pathological evaluation are shown in Table 2. The sensitivity and specificity were calculated from the ROC curve, and the cut-off was decided (Table 3).

\section{The disease-specific survival (DSS)}

The relationship between the DSS and the expression of each molecule is shown in Figure $3 A$. Tumor-infiltrating lymphocytes and CD8+ lymphocytes, intratumoral and intrastromal CD103+ lymphocytes, the tumor diameter, pathological $\mathrm{T}(\mathrm{pT})$, pathological $(\mathrm{pN})$ factor, and the $\mathrm{p}$-stage were significant prognostic factors in the univariate analysis (Table 4). In the multivariate analysis, intratumoral and intrastromal CD103+ lymphocytes and pT and $\mathrm{pN}$ factors were independent prognostic factors (Table 4).

\section{The disease-free survival}

The relationship between the disease-free survival and the expression of each molecule is shown in Figure 3B. Tumorinfiltrating CD8+ lymphocytes, intrastromal CD103+ lymphocytes, PD-L1+ immune cells in the regional lymph nodes, the tumor diameter, $\mathrm{pT}, \mathrm{pN}$ factor, and the p-stage were significant prognostic factors in the univariate analysis (Table 5). In the multivariate analysis, intratumoral CD103+ lymphocyte infiltration, PD-L1+ immune cells in the 
Table 3 Cut-off value for each factor

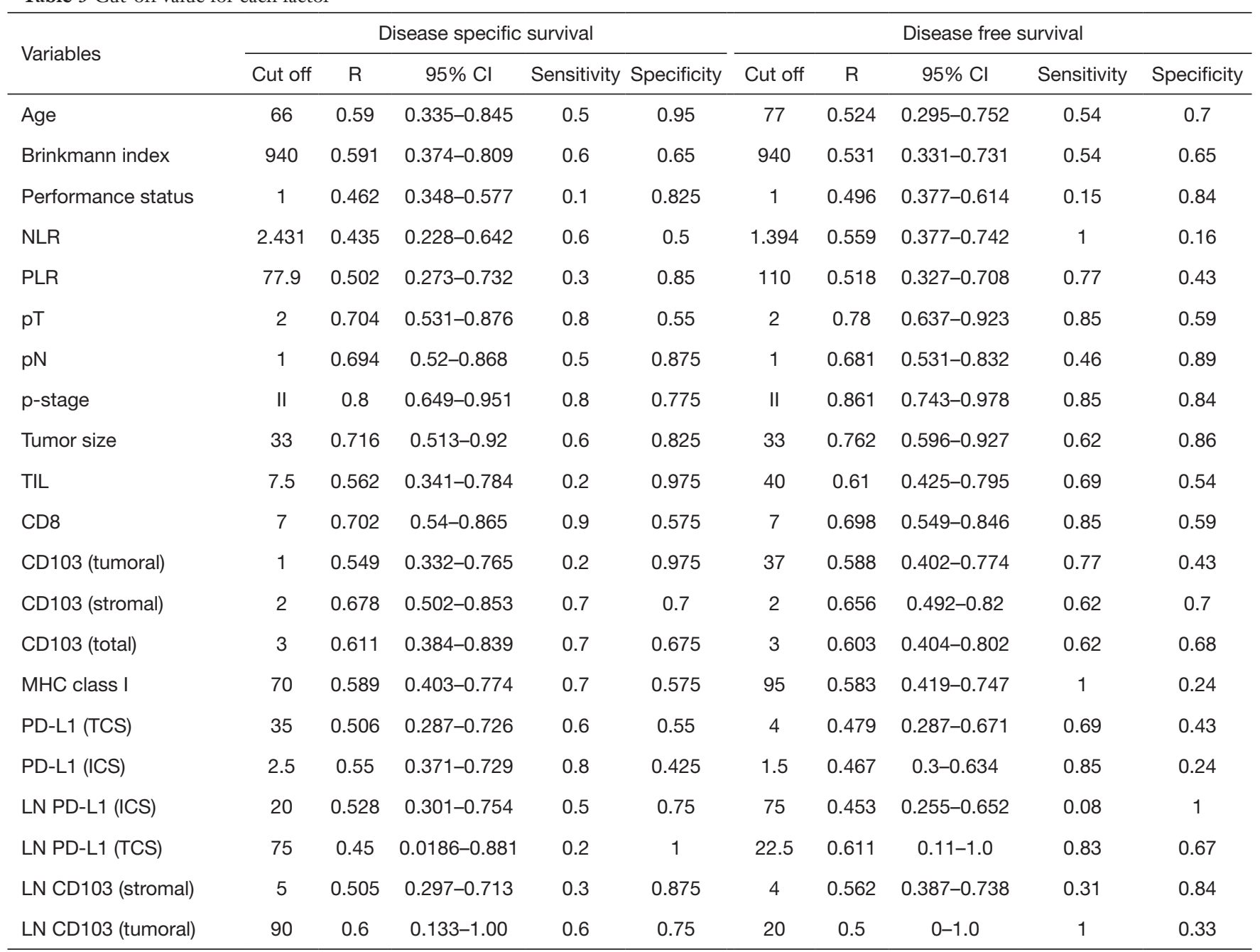

NLR, neutrophil to lymphocyte ratio; PLR, platelet to lymphocyte ratio; TIL, tumor infiltrating lymphocytes; MHC, major histocompatibility complex; PD-L1, programmed cell death protein ligand-1; TCS, tumor cell score; ICS, immune cell score; LN, lymph node.

regional lymph nodes, the tumor diameter, and the p-stage were independent prognostic factors (Table 5).

\section{Immunological tumor microenvironment in primary tumors and regional lymph nodes}

There was significant concordance among accumulations in the tumor of TILs, CD8+ lymphocytes, and CD103+ lymphocytes [including CD 103 (tumoral), CD 103 (stromal), and CD103 (total) lymphocytes] (Figure 4A). However, CD103+ lymphocytes were the only independent prognostic factors in this analysis. While PD-L1 is easily affected by surrounding environmental factors and easily changes both temporally and spatially, there was also significant concordance between the PD-L1 expression of cancer cells in the primary tumors and that in the lymph node metastases (Figure 4B). The PD-L1 expression of cancer cells was also significantly higher in cases in which lymphocytes or CD103+ lymphocytes had infiltrated the tumor nest (Figure 4B). The PD-L1 expression of cancer cells was also significantly higher in cases in which many CD103+ lymphocytes were present in regional lymph nodes (Figure 4B).

\section{The comparison of the molecular expression of cancer cells in primary and metastatic lesions}

The intratumoral infiltration of CD103+ lymphocytes 

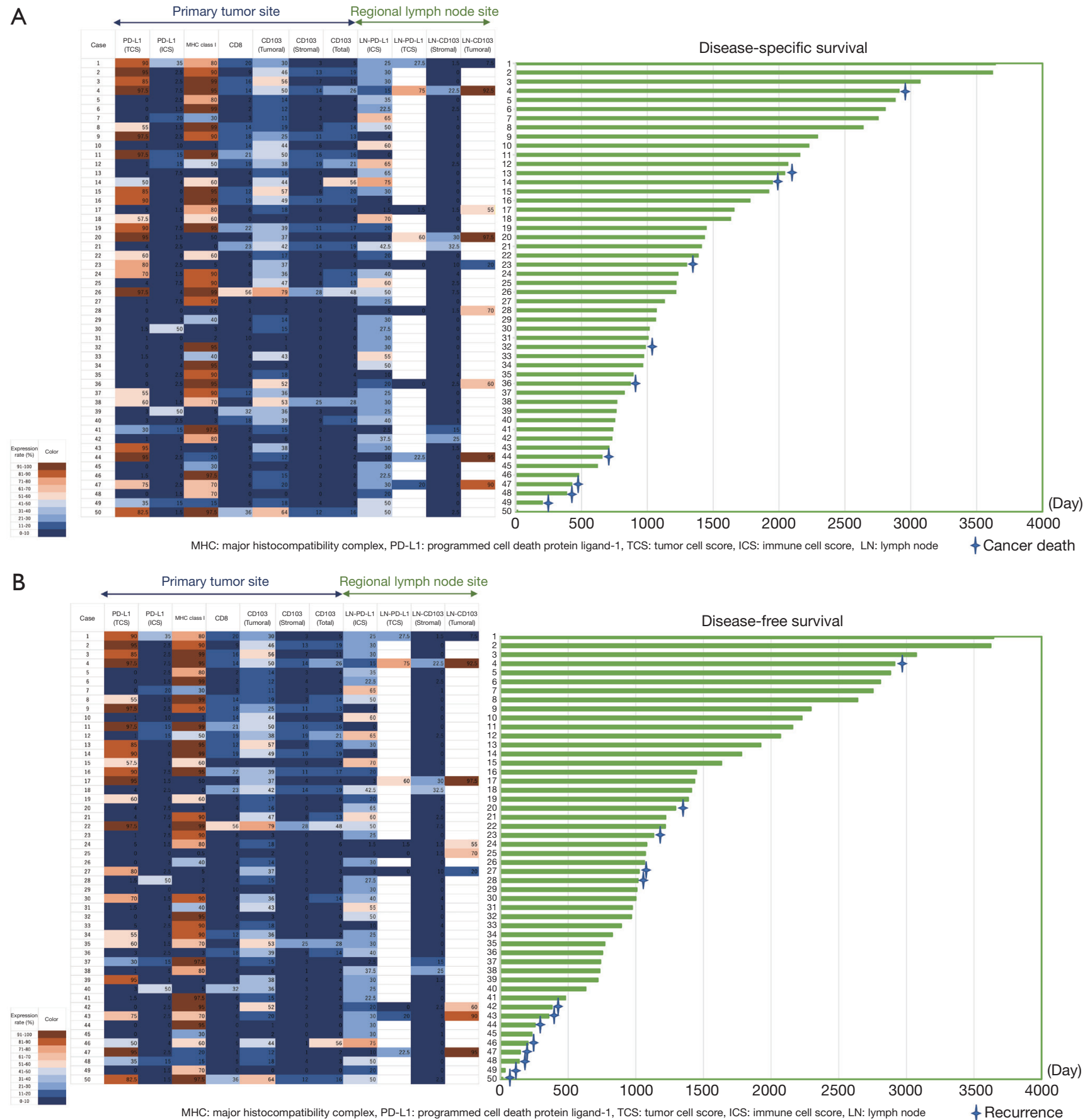

Figure 3 The relationship between the prognosis and the expression of each molecule. (A) The relationship between the disease-specific survival and the expression of each molecule is shown. The left panel shows the expression of each molecule in different colors according to the degree of expression. There were nine cases in which metastasis was found in the regional lymph nodes. The right panel shows the diseasespecific survival for each case. (B) The relationship between the disease-free survival and the expression of each molecule is shown. The left panel shows the expression of each molecule in different colors according to the degree of expression. There were nine cases in which metastasis was found in the regional lymph nodes. The right panel shows the disease-free survival for each case. MHC, major histocompatibility complex; PD-L1, programmed cell death protein ligand-1; TCS, tumor cell score; ICS, immune cell score; LN, lymph node. 
Table 4 Disease-specific survival

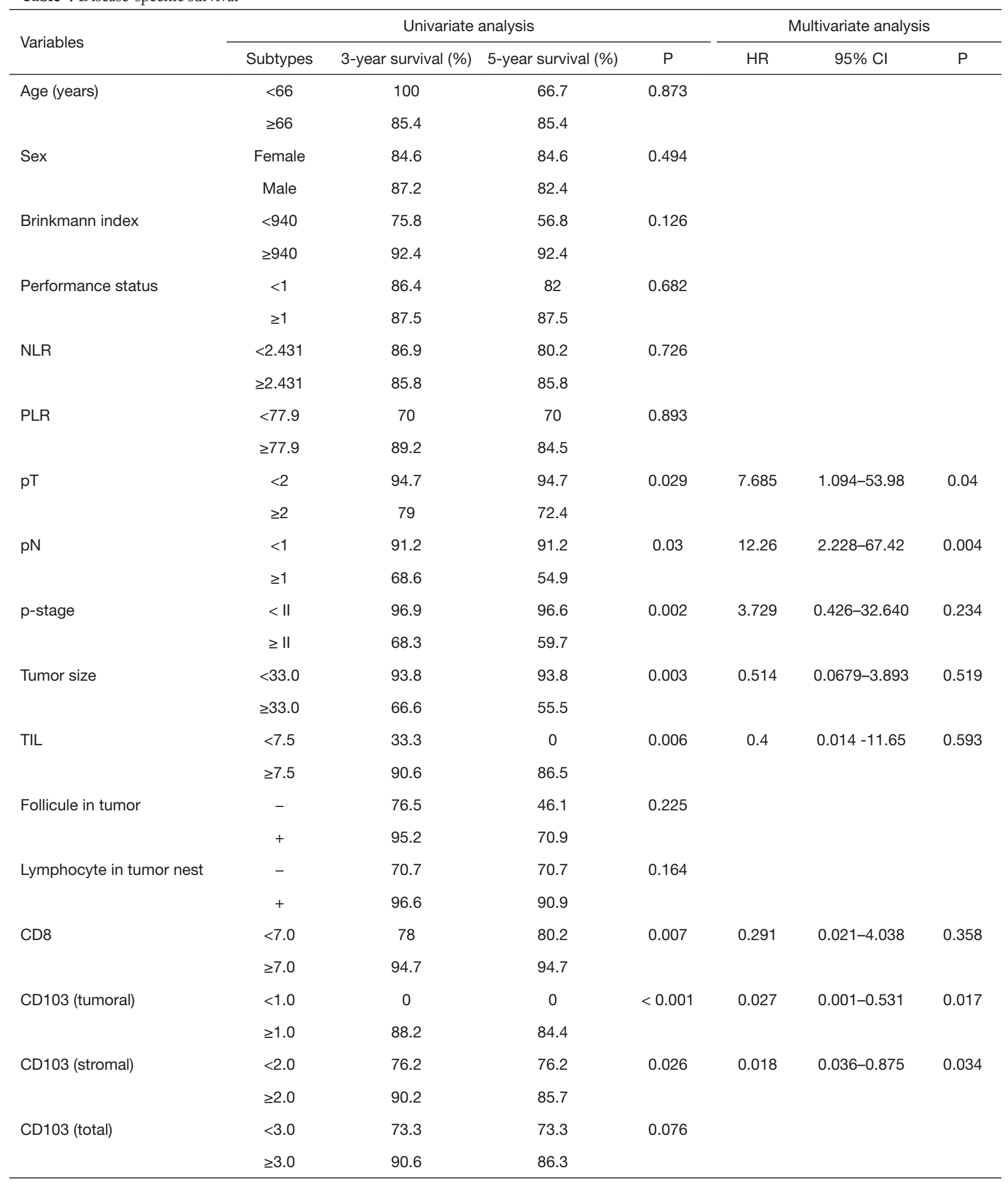

Table 4 (continued) 
Table 4 (continued)

\begin{tabular}{|c|c|c|c|c|c|c|c|}
\hline Variables & \multicolumn{4}{|c|}{ Univariate analysis } & \multicolumn{3}{|c|}{ Multivariate analysis } \\
\hline \multirow[t]{2}{*}{ MHC class I } & $<70$ & 90.2 & 81.2 & 0.36 & & & \\
\hline & $\geq 70$ & 83.5 & 83.5 & & & & \\
\hline PD-L1 (TCS) & $<35$ & 85 & 85 & 0.808 & & & \\
\hline \multirow[t]{2}{*}{ PD-L1 (ICS) } & $<2.5$ & 86.6 & 86.6 & 0.546 & & & \\
\hline & $\geq 2.5$ & 86.4 & 80.6 & & & & \\
\hline \multirow[t]{2}{*}{ LN PD-L1 (ICS) } & $<20$ & 90.9 & 77.9 & 0.191 & & & \\
\hline & $\geq 20$ & 85 & 85 & & & & \\
\hline \multirow[t]{2}{*}{ LN CD103 (stromal) } & $<5.0$ & 86.2 & 86.2 & 0.191 & & & \\
\hline & $\geq 5.0$ & 87.5 & 65.6 & & & & \\
\hline \multirow[t]{2}{*}{ LN CD103 (tumoral) } & $<90$ & 80 & 53.3 & 0.559 & & & \\
\hline & $\geq 90$ & 50 & 50 & & & & \\
\hline
\end{tabular}

NLR, neutrophil to lymphocyte ratio; PLR, platelet to lymphocyte ratio; TIL, tumor infiltrating lymphocytes; MHC, major histocompatibility complex; PD-L1, programmed cell death protein ligand-1; TCS, tumor cell score; ICS, immune cell score; LN, lymph node.

Table 5 Disease-free survival

\begin{tabular}{|c|c|c|c|c|c|c|c|}
\hline Variables & \multicolumn{4}{|c|}{ Univariate analysis } & \multicolumn{3}{|c|}{ Multivariate analysis } \\
\hline \multirow[t]{2}{*}{ Age (years) } & $<77$ & 83.8 & 83.8 & 0.016 & 1.767 & $0.45-6.867$ & 0.411 \\
\hline & $\geq 78$ & 54.3 & 36.2 & & & & \\
\hline Sex & Female & 76.9 & 61.5 & 0.494 & & & \\
\hline \multirow[t]{2}{*}{ Brinkmann index } & $<940$ & 64.5 & 64.5 & 0.346 & & & \\
\hline & $\geq 940$ & 81 & 76.2 & & & & \\
\hline \multirow[t]{2}{*}{ Performance status } & $<1$ & 76.3 & 72 & 0.959 & & & \\
\hline & $\geq 1$ & 65.5 & 65.5 & & & & \\
\hline \multirow[t]{2}{*}{ PLR } & $<110$ & 83.1 & 83.1 & 0.118 & & & \\
\hline & $\geq 110$ & 68.8 & 60.2 & & & & \\
\hline \multirow[t]{2}{*}{ pT } & $<2$ & 95.7 & 95.7 & 0.009 & 2.804 & $0.275-28.55$ & 0.384 \\
\hline & $\geq 2$ & 56.5 & 50.3 & & & & \\
\hline
\end{tabular}

Table 5 (continued) 
Table 5 (continued)

\begin{tabular}{|c|c|c|c|c|c|c|c|}
\hline Variables & \multicolumn{4}{|c|}{ Univariate analysis } & \multicolumn{3}{|c|}{ Multivariate analysis } \\
\hline \multirow[t]{2}{*}{$\mathrm{pN}$} & $<1$ & 83.5 & 78.6 & 0.03 & 1.176 & $0.217-6.388$ & 0.851 \\
\hline & $\geq 1$ & 43.8 & 43.8 & & & & \\
\hline p-stage & $<I I$ & 96.9 & 90.4 & $<0.001$ & 9.226 & $1.933-44.04$ & 0.005 \\
\hline \multirow[t]{2}{*}{ Tumor size } & $<33.0$ & 87.7 & 87.7 & $<0.001$ & 6.974 & $1.760-27.64$ & 0.006 \\
\hline & $\geq 33.0$ & 66.6 & 55.5 & & & & \\
\hline \multirow[t]{2}{*}{ TIL } & $<40$ & 67.5 & 59.1 & 0.122 & & & \\
\hline & $\geq 40$ & 81.2 & 81.2 & & & & \\
\hline \multirow[t]{2}{*}{ Lymphocyte in tumor nest } & - & 68.4 & 57 & 0.082 & & & \\
\hline & + & 79.1 & 79.1 & & & & \\
\hline \multirow[t]{2}{*}{ CD8 } & $<7.0$ & 58.7 & 50.3 & 0.007 & 1.039 & $0.140-7.732$ & 0.971 \\
\hline & $\geq 7.0$ & 90.2 & 90.2 & & & & \\
\hline \multirow[t]{2}{*}{ CD103 (tumoral) } & $<37$ & 67.6 & 60.1 & 0.144 & 0.167 & $0.033-0.842$ & 0.03 \\
\hline & $\geq 37$ & 88.2 & 84.4 & & & & \\
\hline \multirow[t]{2}{*}{ CD103 (stromal) } & $<2.0$ & 68.8 & 0 & 0.038 & 0.392 & $0.084-1.832$ & 0.234 \\
\hline & $\geq 2.0$ & 79.2 & 79.2 & & & & \\
\hline PD-L1 (TCS) & $\geq 4.0$ & 73.3 & 68.4 & & & & \\
\hline \multirow[t]{2}{*}{ PD-L1 (ICS) } & $<1.5$ & 81.8 & 81.8 & 0.686 & & & \\
\hline & $\geq 1.5$ & 73.2 & 68.6 & & & & \\
\hline \multirow[t]{2}{*}{ LNL PD-L1 (ICS) } & $<75$ & 76.2 & 72.4 & 0.001 & 83.57 & $4.118-1,696.0$ & 0.004 \\
\hline & $\geq 75$ & 85 & 85 & & & & \\
\hline \multirow[t]{2}{*}{ LN PD-L1 (TCS) } & $<22.5$ & 0 & 0 & 0.165 & & & \\
\hline & $\geq 22.5$ & 75 & 75 & & & & \\
\hline \multirow[t]{2}{*}{ LN CD103 (stromal) } & $<4.0$ & 77.9 & 73.4 & 0.474 & & & \\
\hline & $\geq 4.0$ & 60 & 60 & & & & \\
\hline \multirow[t]{2}{*}{ LN CD103 (tumoral) } & $<20$ & 100 & 100 & 0.326 & & & \\
\hline & $\geq 20$ & 33.3 & 33.3 & & & & \\
\hline
\end{tabular}

NLR, neutrophil to lymphocyte ratio; PLR, platelet to lymphocyte ratio; TIL, tumor infiltrating lymphocytes; MHC, major histocompatibility complex; PD-L1, programmed cell death protein ligand-1; TCS, tumor cell score; ICS, immune cell score; LN, lymph node. 

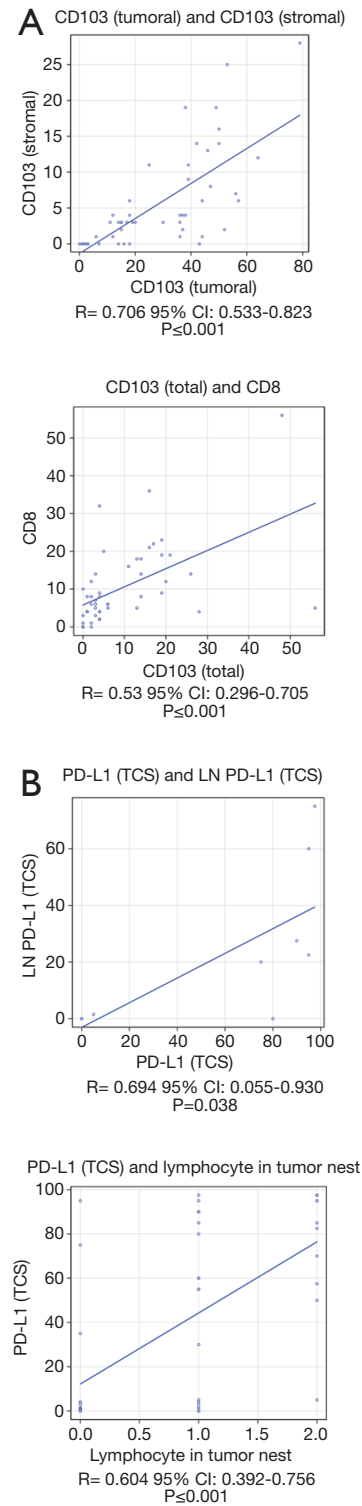

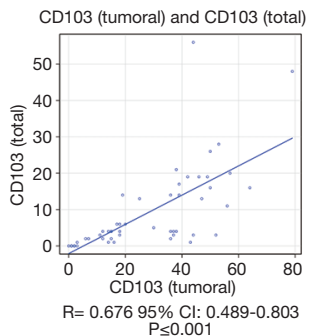

P $\leq 0.00$
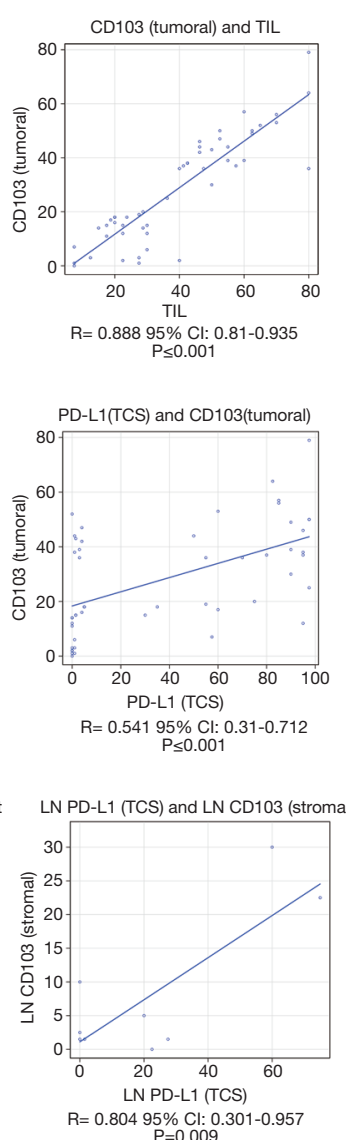
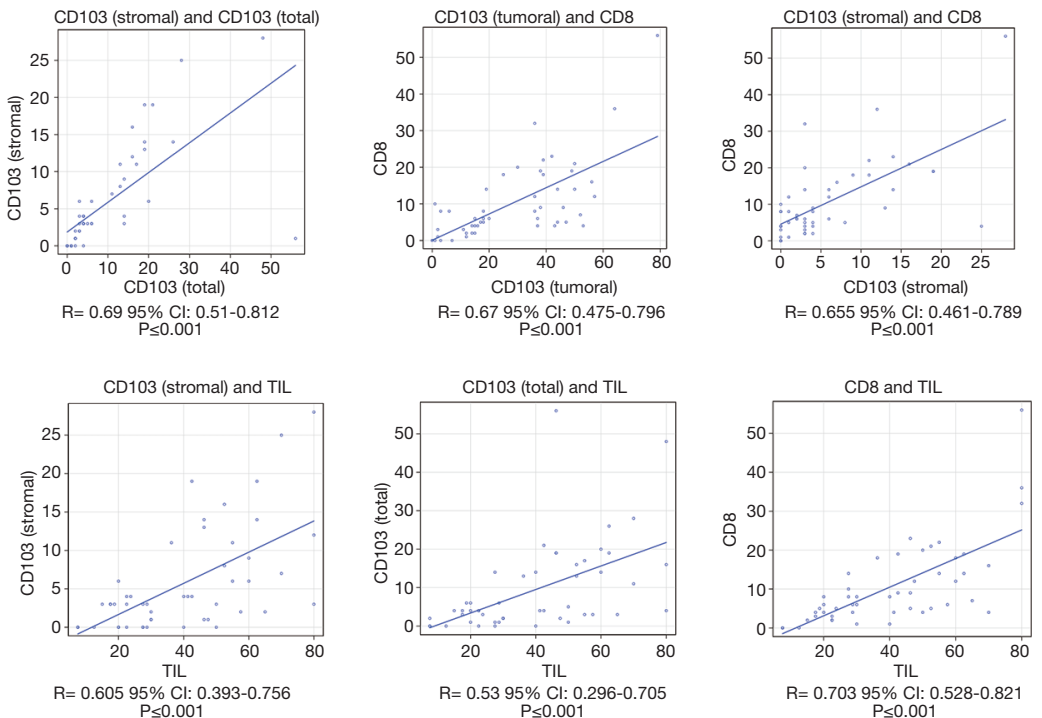

Figure 4 Mutual relationship of immune-related molecular expression (A) Pearson's product-moment correlation coefficient was analyzed to confirm the concordance among the tumor-targeted accumulations of TILs, CD8+ lymphocytes, and CD103+ lymphocytes. (B) Pearson's product-moment correlation coefficient was analyzed to confirm the concordance between the PD-L1 expression of cancer cells in the primary tumors and in lymph node metastases. CI, confidence interval.

was significantly higher in lymph node metastases than in primary tumors, and the PD-L1 expression of cancer cells was also significantly higher in lymph node metastases than in primary tumors (Figure 5).

\section{Discussion}

Cancer-specific lymphocytes are thought to be activated in regional lymph nodes, infiltrate the local cancer, and kill cancer cells (28). Primary tumors and regional lymph nodes are central locations in the effector and priming phases, respectively, and their immunological microenvironment is thought to directly affect the antitumor immune response. However, the types of immune cells involved in the cancer immune response are diverse, and the cancer cells themselves escape from the immune response and thus 

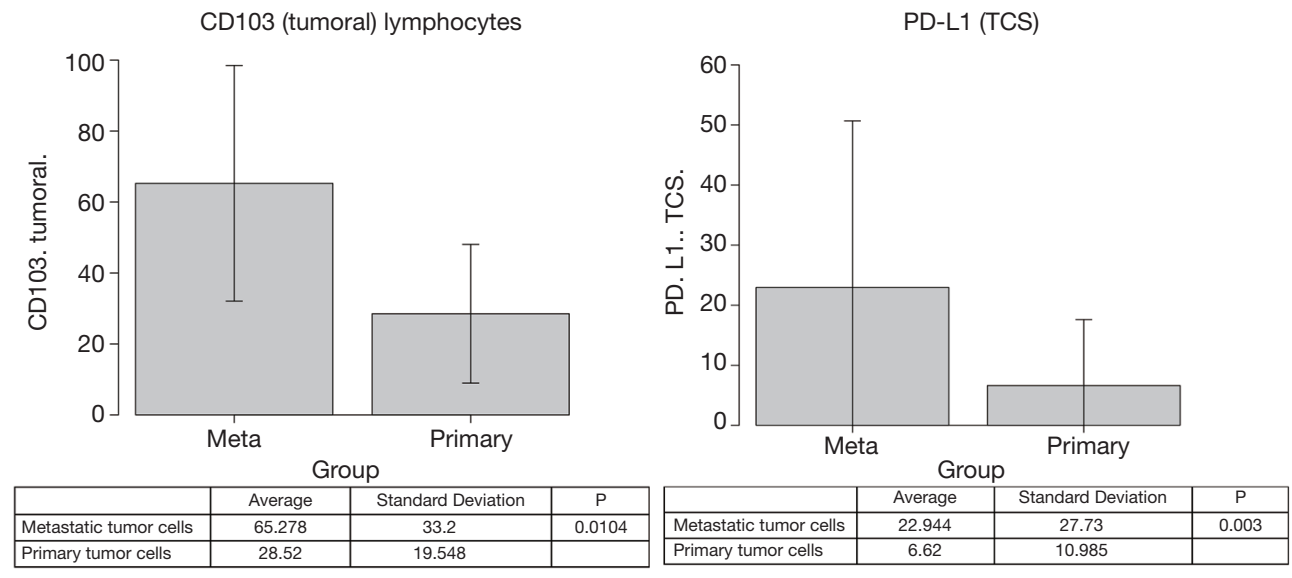

PD-L1: programmed cell death protein ligand-1, TCS: tumor cell score, meta: metastatic tumor cells, primary: primary tumor cells

Figure 5 Comparison of molecular expression of cancer cells in primary and metastatic lesions. The molecular expression of cancer cells in primary and metastatic lesions was compared by a $t$-test. The left panel shows the intratumoral infiltration of CD103+lymphocytes in lymph node metastases and primary tumors. The right panel shows the PD-L1 expression of cancer cells in lymph node metastases and primary tumors. PD-L1, programmed cell death protein ligand-1; TCS, tumor cell score; meta, metastatic tumor cells, primary, primary tumor cells.

alter the expression of immune-related molecules. Indeed, there are many unclear points regarding the relationship between immune cells and cancer cells in primary tumors and regional lymph nodes.

The prognosis is reportedly good in cases in which $\mathrm{T}$ lymphocytes locally infiltrate lung cancer (6). Among T lymphocytes, CD8 T lymphocytes play a central role in killing cancer cells and thus can be sensitive biomarkers. CD8, as we have previously reported, is an essential molecule allowing CTLs to act as effector cells and eliminate cancer cells (29). CD103 is a ligand of E-cadherin, which is an adhesion molecule. CD103+ lymphocytes are cancer-specific lymphocytes, and CD103+ lymphocytes presenting at the tumor site were reported to be a favorable prognostic factor in breast cancer (17). CD103 is mostly expressed in solid tumors but is also expressed by subsets of CD4+ T lymphocytes, natural killer (NK) cells, and dendritic cells. CD103 on T lymphocytes is upregulated by both antigen stimulation and transforming growth factor (TGF)- $\beta$ signaling. CD103 may be a marker for antigeneducated effector $\mathrm{T}$ lymphocytes present in tissues $(30,31)$. CD103 + T lymphocytes appear to be characterized by a lower proliferative potential and higher cytokine production capacity than CD103- T lymphocytes (32), and CD103 is involved in functional interactions between $\mathrm{T}$ cells and epithelial tumor cells $(13,33,34)$. Webb et al. reported that CD103+CD8+ TILs have a higher expression of activation markers HLA-DR, PD-1, and Ki-67 and lower expression of the naïve T cell marker CD127 than do CD103ones (35). In addition, all CD103+ TILs express T-cell intracytoplasmic antigen-1 (TIA-1), a marker of cytolytic potential shown to be a strong prognostic factor in epithelial ovarian cancer (36) and breast cancer (37). There is a strong association between CD103+ TILs and the patient survival. CD103+ TILs are a subset of cytotoxic CD8+ TILs that become highly activated by universally expressing TIA-1. Piet et al. reported that most CD103+ CD8+ T lymphocytes were able to more quickly upregulate cytotoxic mediators than CD103-CD8+ T lymphocytes when they were exposed to their specific antigens upon infection. This allows for a rapid and adequate immune response (38).

We analyzed how often CD103+ lymphocytes are present in the primary tumors and regional lymph nodes of squamous cell lung cancer patients. The effect of the CD103+ lymphocyte accumulation on the prognosis was investigated. In this analysis, TILs and CD8 T lymphocytes were not found to be independent prognostic factors, with only CD103+ T lymphocytes an independent a prognostic factor. Our data also showed that the infiltration of CD103+ $\mathrm{T}$ lymphocytes significantly improved the prognosis and increased the PD-L1 expression of cancer cells.

PD-L1, which was known as B7 homolog 1 (B7-H1) and CD274, was first discovered in 1999 and is located on chromosome 9p24.1. PD-L1 is a member of the CD28+ cytotoxic T lymphocyte-associated protein 4 (CTLA-4) receptor subfamily and is an extremely important 
costimulatory molecule in the immune response, leading to the induction of immune tolerance in the tumor microenvironment (39). PD-L1 is widely expressed on immune cells as well as various cancer cells (40). PD-1, which is a PD-L1 receptor, is also widely expressed on TILs, B lymphocytes, NK cells, monocytes, and dendritic cells. PD-1/PD-L1 is a representative immune checkpoint molecule. PD-L1 has been clinically applied as a predictor of the effect of ICIs but often does not reflect the actual effect of ICIs. In addition, the PD-L1 expression is markedly influenced by the environment around the cells, with strong heterogeneity, so many aspects of its function are unclear.

Rittmeyer et al. reported that atezolizumab, which is a humanized anti-PD-L1 antibody, induced a clinically relevant improvement in the OS in NSCLC patients, regardless of the PD-L1 expression of the cancer cells. Even in cases where PD-L1 is low or undetectable, a significant survival benefit is observed (41). In the present study, as PD-L1 was thought to be involved in CTL reactivation in not only primary tumors but also regional lymph nodes, we confirmed the PD-L1 expression in cancer cells and immune cells in both primary tumors and regional lymph nodes. Since the expression of PD-L1 is heterogeneous and susceptible to the effects of inflammatory cytokines, the expression of PD-L1 of cancer cells in the primary tumors and regional lymph nodes was expected to differ even within the same patient. Surprisingly, however, this analysis showed a positive correlation between the expression of PD-L1 of cancer cells in the primary tumors and regional lymph nodes. If the lymph nodes are not resected, the PDL1 expression of the primary cancer cells may reflect to some extent the expression of lymph node metastases. In addition, the PD-L1 expression of cancer cells was elevated in cases where many lymphocytes and CD103+ lymphocytes had infiltrated the tumor in both primary tumors and regional lymph nodes. Therefore, in cases where primary tumors induce strong immune responses, the regional lymph nodes may also induce strong immune responses. However, in the present analysis, only 9 (18\%) cases had regional lymph node metastases, so further analyses will be required to reach a conclusion.

Conversely, we noted no correlation between the primary tumors and regional lymph nodes in the PDL1 expression of immune cells. In addition, the PD-L1 expression of immune cells in the regional lymph nodes was an independent prognostic factor for a poor DFS. PD-L1 antibody can induce a tumor regression effect even in PD-
L1-negative cancer cells without tumor-infiltrating PDL1+ immune cells, possibly due to the blocking of PD-L1 expression on immune cells in regional lymph nodes.

Chen et al. observed a negative correlation between the PD-L1 expression and CD8+ TIL density in tumors $(r=-0.461, \mathrm{P}<0.001)$. Patients with a high density of CD8+ TILs in tumors showed a better prognosis than those with a low density of cells. The best prognosis for cervical squamous cell carcinoma patients was shown in the high-density PDL1-/CD8+ TIL group, and the worst prognosis was shown in the low-density PD-L1+/CD8+ TIL group (42). Burrack reported that the PD-L1 expression was associated with the CD8+ TIL density in pancreatic cancer tissue, implying the tumor immune response and immunogenicity of tumors (43). The expression of PD-L1 of immune cells was reportedly not associated with lymph node metastasis, tumor stage, nerve infiltration, or vascular infiltration $(44,45)$. Hatogai et al. reported that the PD-L1 expression of cancer cells and immune cells, which were not associated with any clinical or pathological factors, was associated with a good survival of patients with squamous cell carcinoma of the esophagus (46). $\mathrm{Xu}$ et al. suggested that PD-L1 might be an important biomarker of a poor prognosis and certain clinicopathological features of renal cell carcinoma (high TNM stage, poor nuclear grade, necrosis). The upregulation of PD-L1 expression was significantly associated with an increased risk of death [combined relative risk (RR) 2.90, 95\% confidence interval: 1.64-5.13] (47). Shi et al. reported that a significant prognostic effect of the PD-L1 expression of cancer cells was observed only among squamous cell carcinoma of the esophagus patients with a PD-L1 expression rate on immune cells of $<30 \%$ (48). We also previously examined the relationship between the postoperative survival and PDL1 expression patterns of 105 pulmonary neuroendocrine tumor patients. The PD-L1 expression ratios in small cell carcinoma/large cell neuroendocrine carcinoma/typical carcinoid/atypical carcinoid were $26.1 \% / 50 \% / 15.4 \% / 20 \%$, respectively. However, this value was not significantly correlated with the prognoses of any of these patients (49). The influence of the PD-L1 expression by cancer cells on the prognosis varies among studies and remains controversial.

The PD-L1 expression of cancer cells inhibited the immune function of $\mathrm{T}$ cells and induced immune evasion of cancer cells (50). Dendritic cells expressing PD-L1 were unable to activate the proliferation of $\mathrm{CD} 8+\mathrm{T}$ cells, and antibodies against $\mathrm{PD}-\mathrm{L} 1$ were able to restore activation (51). Effector CD8+ T lymphocytes primed in the presence of PD-L1 signaling showed a reduced cytokine production 
and cytotoxic activity compared to CD8+ T lymphocytes in the absence of PD-L1 (52). The upregulation of PDL1 expression on immune cells indicates an inhibitory immune environment, and under the inhibitory immune system, PD-L1 expressed on cancer cells plays a limited role in immunosuppression. The PD-1/PD-L1 signaling pathway has been shown to transmit inhibitory signals to $\mathrm{T}$ lymphocytes and promote immune evasion of cancer cells (53). Batur et al. reported that the concordance of the PD-L1 expression on cancer cells was high between primary NSCLCs and their synchronous brain metastases (54). According to our data, there was also significant concordance between the PD-L1 expression of cancer cells in primary tumors and lymph node metastases. In addition, the PDL1 expression of cancer cells was significantly higher in lymph node metastases than in primary tumors. This may be influenced by the fact that the CD103+ lymphocyte infiltration was significantly higher in lymph node metastases than in primary tumors.

These findings may facilitate the development of more effective immunotherapy. In addition, in the current surgical treatment, all regional lymph nodes were removed in order to eliminate metastatic lesions. However, if an important reaction inducing an effective cancer immune response within regional lymph nodes without lymph node metastasis were to be found, it might be acceptable to consider not resecting the lymph nodes in the future, as ICIs are extremely effective (55).

MHC class I is necessary for cancer cells to present antigens and is the most important molecule allowing lymphocytes to recognize cancer cells. Cancer cells reportedly escape the immune response by reducing the MHC class I expression (56,57). A decreased expression of MHC class I may be a poor prognostic factor, but reports on this point are limited. Changes in MHC class I expression alone reportedly had effect on the OS $(58,59)$. The downregulation of the HLA class I expression was reported in $25-94 \%$ of NSCLCs. We previously analyzed the relationship between the MHC class I expression and the prognosis in 403 resected NSCLC patients and found no significant difference between the groups with a normal and decreased expression (60). Furthermore, 50\% of lung cancer cell lines had abnormalities in their MHC class I expression. The MHC class I expression by cancer cells was absent due to abnormalities in the $\beta 2$-microglobulin ( $\beta 2-\mathrm{m})$ gene, and this expression was restored by the transduction of wild-type $\beta 2-\mathrm{m}$. MHC class I-deficient cells were spared from CTL attack, and reconstitution of the MHC class I expression of cancer cells induced CTL recognition against such cancer cells (61). The tumor antigens presented on MHC class I that was no longer expressed in lung cancer were identified by a cDNA expression cloning method using the tumor-specific CTL clones $(62,63)$. In the present study, 2 (4\%) of 50 squamous cell lung cancers showed $<1 \%$ expression of HLA class I. Our previous analysis showed that these cancer cells without MHC class I expression could escape from CTL attack.

In the present study, the NLR and PLR were not prognostic factors, although the NLR was reported to be an independent poor prognostic factor in cases of NSCLC resection (64). The NLR was also an independent prognostic factor according to multivariate analyses conducted among 44 NSCLC patients receiving ICIs (65). However, in the present analysis, neither the NLR nor the PLR was found to correlate with other immune-related factors or the prognosis. The presence of Treg-containing lymphoid follicles in the tumor of squamous cell carcinoma of the lung was reported to be an independent poor prognostic factor (66), but our analysis did not show any significant difference between lymphoid follicle formation and prognosis. The tumor diameter was reported to be an independent prognostic factor in stage IB NSCLC resection cases (67). Theoretically, as the tumor diameter increases, the effector-to-target ratio decreases, and the antitumor effect consequently decreases. In the present analysis, the tumor diameter was also an independent prognostic factor of the disease-free survival.

This study was limited by its inclusion of old surgical specimens from 2009 and the fact that the analysis evaluated 50 cases (with only 9 cases having regional lymph node metastases). A patient with a 16-day observation period died suddenly from another illness at home.

In the present study, the following points became clear:

(I) Tumor infiltration of TILs, CD8+ lymphocytes, and CD103+ lymphocytes in primary tumors tended to be associated with a good prognosis, but tumor infiltration of CD103+ lymphocytes was particularly strongly associated with a good prognosis.

(II) In both the primary tumors and regional lymph nodes, the PD-L1 expression of cancer cells was increased when lymphocytes, including CD103+ lymphocytes, invaded the tumor.

(III) More CD103+ lymphocytes invaded the tumor, and the PD-L1 expression of cancer cells was also more markedly increased in regional lymph nodes 
than in primary tumors.

(IV) This is the first report comparing the infiltration of various immune cells and the expression of immune-related molecules actually seen in primary tumors and regional lymph nodes of squamous cell lung cancer-bearing patients.

In this study, we analyzed the expression of immunerelated molecules in the primary tumors and regional lymph nodes of patients who underwent resection of squamous cell lung cancer, and the prognosis was particularly good for those with a large amount of CD103+ TILs. The efficacy of ICIs may be expected in cases with marked tumor infiltration of CD103+ lymphocytes.

\section{Acknowledgments}

Funding: Ichiki acknowledges grant support from JSPS KAKENHI (18K08806, 19K09294).

\section{Footnote}

Reporting Checklist: The authors have completed the REMARK reporting checklist. Available at https://dx.doi. org/10.21037/tlcr-21-479

Data Sharing Statement: Available at https://dx.doi. org/10.21037/tlcr-21-479

Peer Review File: Available at https://dx.doi.org/10.21037/ tlcr-21-479

Conflicts of Interest: All authors have completed the ICMJE uniform disclosure form (available at https://dx.doi. org/10.21037/tlcr-21-479). The authors have no conflicts of interest to declare.

Ethical Statement: The authors are accountable for all aspects of the work in ensuring that questions related to the accuracy or integrity of any part of the work are appropriately investigated and resolved. This analysis was performed based on the Declaration of Helsinki (as reviewed in 2013), and the protocol was approved by Saitama Hospital Ethics Committee (R2019-01). Written informed consent was obtained from all the participants for publication of this study.

Open Access Statement: This is an Open Access article distributed in accordance with the Creative Commons
Attribution-NonCommercial-NoDerivs 4.0 International License (CC BY-NC-ND 4.0), which permits the noncommercial replication and distribution of the article with the strict proviso that no changes or edits are made and the original work is properly cited (including links to both the formal publication through the relevant DOI and the license). See: https://creativecommons.org/licenses/by-nc-nd/4.0/.

\section{References}

1. Brahmer J, Reckamp KL, Baas P, et al. Nivolumab versus Docetaxel in Advanced Squamous-Cell Non-Small-Cell Lung Cancer. N Engl J Med 2015;373:123-35.

2. Borghaei H, Paz-Ares L, Horn L, et al. Nivolumab versus Docetaxel in Advanced Nonsquamous Non-Small-Cell Lung Cancer. N Engl J Med 2015;373:1627-39.

3. Herbst RS, Baas P, Kim DW, et al. Pembrolizumab versus docetaxel for previously treated, PD-L1-positive, advanced non-small-cell lung cancer (KEYNOTE-010): a randomised controlled trial. Lancet 2016;387:1540-50.

4. Reck M, Rodríguez-Abreu D, Robinson AG, et al. Pembrolizumab versus Chemotherapy for PD-L1Positive Non-Small-Cell Lung Cancer. N Engl J Med 2016;375:1823-33.

5. Ichiki Y, Takenoyama M, Mizukami M, et al. Simultaneous cellular and humoral immune response against mutated p53 in a patient with lung cancer. J Immunol 2004;172:4844-50.

6. Rakaee M, Kilvaer TK, Dalen SM, et al. Evaluation of tumor-infiltrating lymphocytes using routine $\mathrm{H} \& \mathrm{E}$ slides predicts patient survival in resected non-small cell lung cancer. Hum Pathol 2018;79:188-98.

7. Ruffini E, Asioli S, Filosso PL, et al. Clinical significance of tumor-infiltrating lymphocytes in lung neoplasms. Ann Thorac Surg 2009;87:365-71; discussion 371-2.

8. Naito Y, Saito K, Shiiba K, et al. CD8+ T cells infiltrated within cancer cell nests as a prognostic factor in human colorectal cancer. Cancer Res 1998;58:3491-4.

9. Chiba T, Ohtani H, Mizoi T, et al. Intraepithelial CD8+ T-cell-count becomes a prognostic factor after a longer follow-up period in human colorectal carcinoma: possible association with suppression of micrometastasis. Br J Cancer 2004;91:1711-7.

10. del Rio ML, Bernhardt G, Rodriguez-Barbosa JI, et al. Development and functional specialization of CD103+ dendritic cells. Immunol Rev 2010;234:268-81.

11. Fousteri G, Dave A, Juntti T, et al. CD103 is dispensable for anti-viral immunity and autoimmunity in a mouse 
model of virally-induced autoimmune diabetes. J

Autoimmun 2009;32:70-7.

12. Erle DJ, Brown T, Christian D, et al. Lung epithelial lining fluid $\mathrm{T}$ cell subsets defined by distinct patterns of beta 7 and beta 1 integrin expression. Am J Respir Cell Mol Biol 1994;10:237-44.

13. Agace WW, Higgins JM, Sadasivan B, et al. T-lymphocyteepithelial-cell interactions: integrin alpha(E)(CD103) beta(7), LEEP-CAM and chemokines. Curr Opin Cell Biol 2000;12:563-8.

14. de Vries IJ, Langeveld-Wildschut EG, van Reijsen FC, et al. Nonspecific T-cell homing during inflammation in atopic dermatitis: expression of cutaneous lymphocyteassociated antigen and integrin alphaE beta 7 on skin-infiltrating T cells. J Allergy Clin Immunol 1997;100:694-701.

15. Shin H, Iwasaki A. Tissue-resident memory T cells. Immunol Rev 2013;255:165-81.

16. Massi D, Romano E, Rulli E, et al. Baseline $\beta$-catenin, programmed death-ligand 1 expression and tumourinfiltrating lymphocytes predict response and poor prognosis in BRAF inhibitor-treated melanoma patients. Eur J Cancer 2017;78:70-81.

17. Wang ZQ, Milne K, Derocher H, et al. CD103 and Intratumoral Immune Response in Breast Cancer. Clin Cancer Res 2016;22:6290-7.

18. Komdeur FL, Wouters MC, Workel HH, et al. CD103+ intraepithelial $\mathrm{T}$ cells in high-grade serous ovarian cancer are phenotypically diverse TCR $\alpha \beta+\operatorname{CD} 8 \alpha \beta+\mathrm{T}$ cells that can be targeted for cancer immunotherapy. Oncotarget 2016;7:75130-44.

19. Lohneis P, Sinn M, Bischoff S, et al. Cytotoxic tumourinfiltrating $\mathrm{T}$ lymphocytes influence outcome in resected pancreatic ductal adenocarcinoma. Eur J Cancer 2017;83:290-301.

20. Brahmer JR, Drake CG, Wollner I, et al. Phase I study of single-agent anti-programmed death-1 (MDX1106) in refractory solid tumors: safety, clinical activity, pharmacodynamics, and immunologic correlates. J Clin Oncol 2010;28:3167-75.

21. Templeton AJ, McNamara MG, Šeruga B, et al. Prognostic role of neutrophil-to-lymphocyte ratio in solid tumors: a systematic review and meta-analysis. J Natl Cancer Inst 2014;106:dju124.

22. Liu H, Wu Y, Wang Z, et al. Pretreatment platelet-tolymphocyte ratio (PLR) as a predictor of response to firstline platinum-based chemotherapy and prognosis for patients with non-small cell lung cancer. J Thorac Dis
2013;5:783-9.

23. Kaya V, Yildirim M, Demirpence O, et al. Prognostic significance of basic laboratory methods in non- smallcell-lung cancer. Asian Pac J Cancer Prev 2013;14:5473-6.

24. Diem S, Schmid S, Krapf M, et al. Neutrophil-toLymphocyte ratio (NLR) and Platelet-to-Lymphocyte ratio (PLR) as prognostic markers in patients with nonsmall cell lung cancer (NSCLC) treated with nivolumab. Lung Cancer 2017;111:176-81.

25. McShane LM, Altman DG, Sauerbrei W, et al. REporting recommendations for tumour MARKer prognostic studies (REMARK). Br J Cancer 2005;93:387-91.

26. Goldstraw P, Chansky K, Crowley J, et al. The IASLC Lung Cancer Staging Project: Proposals for Revision of the TNM Stage Groupings in the Forthcoming (Eighth) Edition of the TNM Classification for Lung Cancer. J Thorac Oncol 2016;11:39-51.

27. Kanda Y. Investigation of the freely available easy-touse software 'EZR' for medical statistics. Bone Marrow Transplant 2013;48:452-8.

28. Chen DS, Mellman I. Oncology meets immunology: the cancer-immunity cycle. Immunity 2013;39:1-10.

29. Ichiki Y, Shigematsu Y, Baba T, et al. Development of adoptive immunotherapy with KK-LC-1-specific TCRtransduced $\gamma \delta \mathrm{T}$ cells against lung cancer cells. Cancer Sci 2020;111:4021-30.

30. Gorfu G, Rivera-Nieves J, Ley K. Role of beta7 integrins in intestinal lymphocyte homing and retention. Curr Mol Med 2009;9:836-50.

31. Thome JJ, Farber DL. Emerging concepts in tissueresident T cells: lessons from humans. Trends Immunol 2015;36:428-35.

32. Park CO, Kupper TS. The emerging role of resident memory $\mathrm{T}$ cells in protective immunity and inflammatory disease. Nat Med 2015;21:688-97.

33. Franciszkiewicz K, Le Floc'h A, Boutet M, et al. CD103 or LFA-1 engagement at the immune synapse between cytotoxic $\mathrm{T}$ cells and tumor cells promotes maturation and regulates T-cell effector functions. Cancer Res 2013;73:617-28.

34. Ling KL, Dulphy N, Bahl P, et al. Modulation of CD103 expression on human colon carcinoma-specific CTL. J Immunol 2007;178:2908-15.

35. Webb JR, Milne K, Watson P, et al. Tumor-infiltrating lymphocytes expressing the tissue resident memory marker CD103 are associated with increased survival in high-grade serous ovarian cancer. Clin Cancer Res 2014;20:434-44. 
36. Milne K, Köbel M, Kalloger SE, et al. Systematic analysis of immune infiltrates in high-grade serous ovarian cancer reveals CD20, FoxP3 and TIA-1 as positive prognostic factors. PLoS One 2009;4:e6412.

37. West NR, Milne K, Truong PT, et al. Tumor-infiltrating lymphocytes predict response to anthracycline-based chemotherapy in estrogen receptor-negative breast cancer. Breast Cancer Res 2011;13:R126.

38. Piet B, de Bree GJ, Smids-Dierdorp BS, et al. $\mathrm{CD}^{+} \mathrm{T}$ cells with an intraepithelial phenotype upregulate cytotoxic function upon influenza infection in human lung. J Clin Invest 2011;121:2254-63.

39. Wang S, Li J, Xie J, et al. Programmed death ligand 1 promotes lymph node metastasis and glucose metabolism in cervical cancer by activating integrin $\beta 4 /$ SNAI1/SIRT3 signaling pathway. Oncogene 2018;37:4164-80.

40. Madore J, Strbenac D, Vilain R, et al. PD-L1 Negative Status is Associated with Lower Mutation Burden, Differential Expression of Immune-Related Genes, and Worse Survival in Stage III Melanoma. Clin Cancer Res 2016;22:3915-23.

41. Rittmeyer A, Barlesi F, Waterkamp D, et al. Atezolizumab versus docetaxel in patients with previously treated non-small-cell lung cancer (OAK): a phase 3, openlabel, multicentre randomised controlled trial. Lancet 2017;389:255-65.

42. Chen J, Gu P, Wu H. Uncovering PD-L1 and CD8+ TILS Expression and Clinical Implication in Cervical Squamous Cell Carcinoma. Biomed Res Int 2020;2020:8164365.

43. Burrack AL, Spartz EJ, Raynor JF, et al. Combination PD-1 and PD-L1 Blockade Promotes Durable Neoantigen-Specific T Cell-Mediated Immunity in Pancreatic Ductal Adenocarcinoma. Cell Rep 2019;28:2140-2155.e6.

44. Chen MF, Chen PT, Chen WC, et al. The role of PD$\mathrm{L} 1$ in the radiation response and prognosis for esophageal squamous cell carcinoma related to IL-6 and T-cell immunosuppression. Oncotarget 2016;7:7913-24.

45. Jiang Y, Lo AWI, Wong A, et al. Prognostic significance of tumor-infiltrating immune cells and PD-L1 expression in esophageal squamous cell carcinoma. Oncotarget 2017;8:30175-89.

46. Hatogai K, Kitano S, Fujii S, et al. Comprehensive immunohistochemical analysis of tumor microenvironment immune status in esophageal squamous cell carcinoma. Oncotarget 2016;7:47252-64.

47. Xu F, Xu L, Wang Q, et al. Clinicopathological and prognostic value of programmed death ligand-1 (PD-L1) in renal cell carcinoma: a meta-analysis. Int J Clin Exp Med 2015;8:14595-603.

48. Shi F, Xiao S, Miller KB, et al. Interactive Effects of PDL1 Expression in Tumor and Immune Cells on Prognosis of Esophageal Squamous Cell Carcinoma: A OneCenter Retrospective Cohort Study. Onco Targets Ther 2020;13:6565-72.

49. Ichiki Y, Matsumiya H, Mori M, et al. Predictive factors of postoperative survival among patients with pulmonary neuroendocrine tumor. J Thorac Dis 2018;10:6912-20.

50. Juneja VR, McGuire KA, Manguso RT, et al. PD$\mathrm{L} 1$ on tumor cells is sufficient for immune evasion in immunogenic tumors and inhibits CD8 T cell cytotoxicity. J Exp Med 2017;214:895-904.

51. Pulko V, Liu X, Krco CJ, et al. TLR3-stimulated dendritic cells up-regulate $\mathrm{B} 7-\mathrm{H} 1$ expression and influence the magnitude of CD8 $\mathrm{T}$ cell responses to tumor vaccination. J Immunol 2009;183:3634-41.

52. Benedict CA, Loewendorf A, Garcia Z, et al. Dendritic cell programming by cytomegalovirus stunts naive $T$ cell responses via the PD-L1/PD-1 pathway. J Immunol 2008; 180:4836-47.

53. Bour-Jordan H, Esensten JH, Martinez-Llordella M, et al. Intrinsic and extrinsic control of peripheral T-cell tolerance by costimulatory molecules of the CD28/B7 family. Immunol Rev 2011;241:180-205.

54. Batur S, Dulger O, Durak S, et al. Concordance of PDL1 expression and CD8+ TIL intensity between NSCLC and synchronous brain metastases. Bosn J Basic Med Sci 2020;20:329-35.

55. Ichiki Y, Fukuyama T, Nakanishi K. The prospect of combination therapy with immune checkpoint inhibitors and chemotherapy for squamous cell carcinoma of the lung. Transl Lung Cancer Res 2020;9:811-5.

56. Cordon-Cardo C, Fuks Z, Drobnjak M, et al. Expression of HLA-A,B,C antigens on primary and metastatic tumor cell populations of human carcinomas. Cancer Res 1991;51:6372-80.

57. Campo MS, Graham SV, Cortese MS, et al. HPV16 E5 down-regulates expression of surface HLA class I and reduces recognition by CD8 T cells. Virology 2010;407:137-42.

58. Yoo SH, Keam B, Ock CY, et al. Prognostic value of the association between MHC class I downregulation and PDL1 upregulation in head and neck squamous cell carcinoma patients. Sci Rep 2019;9:7680.

59. Wuerdemann N, Gültekin SE, Pütz K, et al. PDL1 Expression and a High Tumor Infiltrate of CD8+ 
Lymphocytes Predict Outcome in Patients with Oropharyngeal Squamous Cells Carcinoma. Int J Mol Sci 2020;21:5228.

60. Hanagiri T, Shigematsu Y, Kuroda K, et al. Prognostic implications of human leukocyte antigen class I expression in patients who underwent surgical resection for nonsmall-cell lung cancer. J Surg Res 2013;181:e57-63.

61. Baba T, Hanagiri T, Ichiki Y, et al. Lack and restoration of sensitivity of lung cancer cells to cellular attack with special reference to expression of human leukocyte antigen class I and/or major histocompatibility complex class I chain related molecules A/B. Cancer Sci 2007;98:1795-802.

62. So T, Takenoyama M, Mizukami M, et al. Haplotype loss of HLA class I antigen as an escape mechanism from immune attack in lung cancer. Cancer Res 2005;65:5945-52.

63. Baba T, Hanagiri T, Takenoyama M, et al. Identification of a lung cancer antigen evading CTL attack due to loss of

Cite this article as: Ichiki $\mathrm{Y}$, Ueno M, Yanagi S, Kanasaki Y, Goto H, Fukuyama T, Mikami S, Nakanishi K, Ishida T. An analysis of the immunological tumor microenvironment of primary tumors and regional lymph nodes in squamous cell lung cancer. Transl Lung Cancer Res 2021;10(8):3520-3537. doi: $10.21037 /$ tlcr-21-479 human leukocyte antigen (HLA) class I expression. Cancer Sci 2010;101:2115-20.

64. Shimizu K, Okita R, Saisho S, et al. Preoperative neutrophil/lymphocyte ratio and prognostic nutritional index predict survival in patients with non-small cell lung cancer. World J Surg Oncol 2015;13:291.

65. Ichiki Y, Taira A, Chikaishi Y, et al. Prognostic factors of advanced or postoperative recurrent non-small cell lung cancer targeted with immune check point inhibitors. J Thorac Dis 2019;11:1117-23.

66. Nishihira M, Nakazato Y, Maeda S, et al. Impact of tumor infiltrating lymphocytes and lymphoid follicle formation on patient survival following surgery for lung squamous cell carcinoma. Thorac Cancer 2019;10:219-25.

67. Xu S, Xi J, Jiang W, et al. Solid component and tumor size correlate with prognosis of stage IB lung adenocarcinoma. Ann Thorac Surg 2015;99:961-7. 